\title{
B Lymphocytes from X-Linked Agammaglobulinemia Delayed Expression of Light Chain and Demonstration of Lyonization in Carriers
}

\author{
Jerrold Schwaber, Jennifer Payne, and Raymond Chen \\ Children's Hospital-Boston, and Department of Pathology, Harvard Medical School, Boston, Massachusetts 02115
}

\begin{abstract}
We report an unusual phenotype of $B$ cells in a patient with X-linked agammaglobulinemia (XLA), and cellular evidence for Lyonization of $B$ cells from his mother and sister. The patient has a failure of $B$ cell maturation at the stage of early $B$ lymphocytes, associated with production of $\mathrm{D}(\mu \delta) \mathrm{H}$ chain. The phenotype of his B cells includes: $(a)$ limitation to expression of the $\mu$ and $\delta \mathrm{H}$ chain isotypes, (b) production of $\mu$ and $\delta \mathrm{H}$ chains of reduced size and $(c)$ delayed expression of $L$ chain. Peripheral blood and B cell lines from the patient's mother and sister include $50 \%$ cells that express $H$ chain without $L$ chain. $B$ cell lines from the mother and sister produce full-length $\mu$ and gamma $H$ chains and truncated $\mu$ and $\delta$ chains corresponding to the $H$ chains produced by the patient's $B$ cells. Clones with normal and XLA phenotype have been isolated from $B$ cell lines derived from the patient's mother. We conclude that the dimorphism of mother's and sister's B cells results from Lyonization, implying that the gene defect in XLA is intrinsic to B lymphocytes.
\end{abstract}

\section{Introduction}

$\mathrm{X}$-linked agammaglobulinemia (XLA) ${ }^{1}$ is a sex-linked, congenital antibody deficiency disease associated with failure of $B$ lymphocyte differentiation, either at the level of pre-B cells (major form) or at the level of early B lymphocytes (minor form) (1-9). Whether the heterogeneity of the stage at which B cell maturation fails is due to distinct $\mathrm{X}$-linked defects or results from variable expression of the same defect has not been determined. The disease is not linked to the $\mathrm{Xg}$ blood group $(10,11)$, and other polymorphic protein markers have been uninformative in these families. Recently, XLA in families with the major form of the disease has been linked to Xq2 by restriction fragment length polymorphisms (12). Evidence for Lyonization (13) in carriers of the major form of XLA has now been reported in one family that carries a polymorphism for G-6-PD (14) and in two families with a restriction fragment length polymorphism based upon methylation of the genomic

Address reprint requests to Dr. Schwaber, Immunology Division, Children's Hospital, 300 Longwood Avenue, Boston, MA 02115.

Received for publication 31 January 1986 and in revised form 24 August 1987.

1. Abbreviations used in this paper: Ckappa, constant human genomic kappa L chain; TMRITC, tetramethyl rhodamine isothiocyanate; XLA, X-linked agammaglobulinemia.

J. Clin. Invest.

(C) The American Society for Clinical Investigation, Inc.

0021-9738/88/02/0514/09\$2.00

Volume 81, February 1988, 514-522 sequences for hypoxanthine phosphoribosyl transferase (HPRT) and phosphoglycerol kinase (PGK) (15). In both cases, the evidence for Lyonization was the random expression of both chromosomes in $\mathrm{T}$ cells and monocytes, but absence of expression of the affected $\mathrm{X}$ chromosome in $\mathrm{B}$ cells.

We have recently found that the B lymphocytes of a boy with the minor form of XLA produce truncated $\mu$ and $\delta \mathrm{H}$ chains composed of $\mathrm{D}-\mathrm{J}_{\mathrm{H}}-\mathrm{C}(\mu \delta)(\mathrm{D} \mu \delta)$ resulting from abortive rearrangement of variable region genes (Schwaber, J., and R. Chen, submitted for publication). Associated with, and in part resulting from, this defect in gene rearrangement, his B lymphocytes have a unique phenotype that includes $(a)$ restriction to expression of the $\delta$ and $\mu \mathrm{H}$ chain isotypes, $(b)$ limited expression of $\mathrm{L}$ chains, exclusively of the kappa isotype, and (c) reduction in size of the $\delta$ and $\mu \mathrm{H}$ chains. In contrast to carriers of the major form of XLA, whose pre-B cells do not enter peripheral circulation, Lyon's hypothesis (13) predicts that carriers of this form of XLA gene should have a dimorphic population of B lymphocytes, composed of clones of normal phenotype, and clones of the phenotype of their affected relatives.

We report the delayed expression of $\mathrm{L}$ chains by this boy's B lymphocytes, and provide evidence for Lyonization of his mother's and sister's B lymphocytes. Limited numbers of the patient's peripheral blood B lymphocytes express $L$ chains. Newly established B cell lines include limited numbers of cells that express $\mathrm{L}$ chain. In continuous culture, increasing numbers of cells express $\mathrm{L}$ chain exclusively of the kappa isotype. $\mathrm{L}$ chain expression by $B$ cells is clonal, and appears not to be regulated by $L$ chain gene rearrangement. Approximately one-half of B lymphocytes from the patient's mother do not express immunoglobulin $\mathrm{L}$ chain. B cell lines derived from her peripheral blood are also dimorphic, containing cells producing full length $\mu$ and $\gamma \mathrm{H}$ chains and cells producing truncated $\mu$ - and $\delta$-chains. Cells that do not express L chain express only $\mu$ or $\delta \mathrm{H}$ chain, and cells that express gamma chain always express $\mathrm{L}$ chain. Clones that produce truncated $\delta$-chain have delayed expression of L chain only of the kappa isotype, while a clone that expresses gamma chain coexpresses $\mathrm{L}$ chain from the time of isolation. In addition, we find that the patient's sister has the same dimorphic B lymphocyte phenotype as her mother, suggesting that she is a carrier of XLA.

\section{Methods}

The patient has been identified in previous publications as 4-8 $(6,7$, 16). His family consists of mother, stepfather, and maternal half-sister (referred to as sister in the remainder of this manuscript). The diagnosis of XLA is based upon onset of the disease in early childhood and agammaglobulinemia in his maternal uncle from early childhood (3). The patient has normal numbers of peripheral B lymphocytes with phenotype limited to $\delta$ and $\mu \mathrm{H}$ chains $(7,17)$.

Peripheral blood was obtained by venipuncture and the mononu- 
clear cells were isolated by buoyant density gradient centrifugation on Ficoll-Hypaque (18). B cell lines were established as previously described (19), using Epstein-Barr virus from the B95-8 cell line. Clones were isolated in soft agarose with fibroblast feeder cells suspended in the agarose, as previously described (20).

Immune fluorescence was with $\mathrm{Fab}_{2}^{\prime}$ fragments of goat antisera (Cappel Laboratories, Cochranville, PA) cross-absorbed with other Ig isotypes coupled to Sepharose 4B. Cells were either stained directly with antisera conjugated with FITC or tetramethyl rhodamine isothiocyanate (TMRITC) as previously described (17), or stained indirectly with mouse monoclonal antibodies to kappa and lambda $L$ chains and sheep antiserum to mouse IgG conjugated with Texas Red. Live cells ( $>95 \%$ viable) were stained at $4^{\circ} \mathrm{C}$, and examined immediately. Fixed cells were placed on microscope slides with a cytocentrifuge, stained at room temperature, and examined immediately.

Ig proteins were examined by internal labeling with $\left[{ }^{35} \mathrm{~S}\right]$ methionine. 2 to $3 \times 10^{6}$ cells were incubated in Eagle's MEM without methionine, supplemented with $10 \%$ dialyzed FBS, and $100 \mu \mathrm{Ci}$ of $\left[{ }^{35} \mathrm{~S}\right] \mathrm{me}-$ thionine/ml for 2-4 h. Cytoplasmic proteins were liberated from cell pellets by lysis with $0.5 \%$ NP-40 (21). Supernatants of the 4-h culture were reserved for examination of secreted proteins. Labeled immunoglobulins were isolated either by precipitation with isotype specific rabbit antibody and formalin fixed Staphylococcus A (IgSorb), or by precipitation with isotype specific rabbit antibody and goat antiserum to rabbit IgG at equivalence (22). Because of specific reactivity of Staph A with human $\operatorname{IgM}, \mathrm{IgD}$, and $\mathrm{IgG}$, the isotypes of protein bands were identified by indirect precipitation with goat antiserum (22).

Immune precipitates were redissolved in $2 \%$ SDS and $1 \% 2$-mercaptoethanol, boiled for $2 \mathrm{~min}$, and electrophoresed in 12.5\% SDSacrylamide discontinuous slab gels. The gels and buffers were prepared exactly as described by Dreyfuss et al. (23). They were fixed, processed for fluorography, and exposed to x-ray film. Unlabeled, reduced and alkylated, normal human IgG and IgM, and BSA were used as molecular weight standards, in addition to labeled $\mu$ and $L$ chains from the normal B cell line SMI4.

Genomic DNA was extracted from pelleted cells as previously described (24) and digested to completion with the restriction endonuclease Bam H1. Digested DNA (10 $\mu \mathrm{g}$ per lane) was electrophoresed in $0.8 \%$ agarose, and transferred to nitrocellulose as described by Southern (25). The filter was probed with a 2.5-kb Eco R1 subclone of the phage clone of the constant region of human genomic kappa $L$ chain (Ckappa) (kindly provided by P. Leder, Harvard Medical School, Boston, MA) (26), labeled by the OLB random priming method with $\left[{ }^{32} \mathrm{P}\right] \mathrm{dCTP}(27)$. It was then washed to $0.1 \times$ SSC with $0.1 \%$ SDS at $65^{\circ} \mathrm{C}(24)$, and exposed to $x$-ray film at $-80^{\circ} \mathrm{C}$ with intensifying screen for $48 \mathrm{~h}$.

\section{Results}

$L$ chain expression by $X L A B$ cells. We have previously shown that the patient's B cells are limited to expression of $\mathbf{H}$ chain of the $\delta$ and $\mu$ isotypes (7), and that the $\mu$ and $\delta$ chains are truncated forms composed only of D- $\mathrm{J}_{\mathrm{H}}-\mathrm{C}(\delta \mu)$ (Schwaber, J., and R. Chen, submitted for publication). L chain expression by his peripheral blood lymphocytes was determined using both direct antisera and mouse monoclonal antibodies indirectly stained with second antibody. B cells were identified by counter-staining with antiserum to $\mu$ and $\delta \mathrm{H}$ chains conjugated with FITC. Examination of live cells by direct staining revealed 7 cells expressing kappa $\mathrm{L}$ chain of $500 \mathrm{H}$ chain positive cells (Table I). No cells expressing lambda chain were identified. Reexamination of his peripheral blood B cells by indirect staining with a mouse monoclonal antibody revealed six L chain fluorescent cells of 500 B cells. Repeated examination of fixed cells yielded identical results. Tests for background staining with these antisera on the T cell line CEM, the mouse myeloma cell line RPC 5.4, and the human fetal liver pre-B cell hybrid LSH6, suggested that the $1 \% \mathrm{~L}$ chain fluorescent cells in peripheral blood represent true $L$ chain staining.

Two recently established B cell lines, LAZ 166 from the patient's peripheral blood, and SB 25 from his bone marrow, were examined for expression of $L$ chain. From LAZ 166, no $L$ chain fluorescent cells were found, by staining with either direct or indirect antisera, and examining both live and fixed cells (Fig. 1, Table II). From SB 25, 4\% of the cells expressed L chain. All of these cells were of the kappa isotype.

Since the limited expression of $L$ chain by the $B$ cell lines was in distinction to our previous observations of kappa $\mathrm{L}$ chain expression by most of the cells from LAZ 166 (7), we examined samples of LAZ 166 that had been frozen after varying periods of time in culture. Continuous culture of LAZ 166 was associated with increased expression of $L$ chain. A culture grown continuously for 2 mo had $0.5 \% \mathrm{~L}$ chain bearing cells ( $2 \%$ of $\mathrm{H}$ chain-bearing cells), a culture grown for $6 \mathrm{mo}$ had $15 \% \mathrm{~L}$ chain-bearing cells ( $48 \%$ of $\mathrm{H}$ chain-bearing cells), and a culture that had been grown continuously for 1 yr had 23\% L chain-bearing cells ( $82 \%$ of $\mathrm{H}$ chain bearing cells; Table III).

LAZ 166 had been cloned in soft agar after $\sim 3 \mathrm{mo}$ in

Table I. Immune Fluorescence of Peripheral Blood Lymphocytes

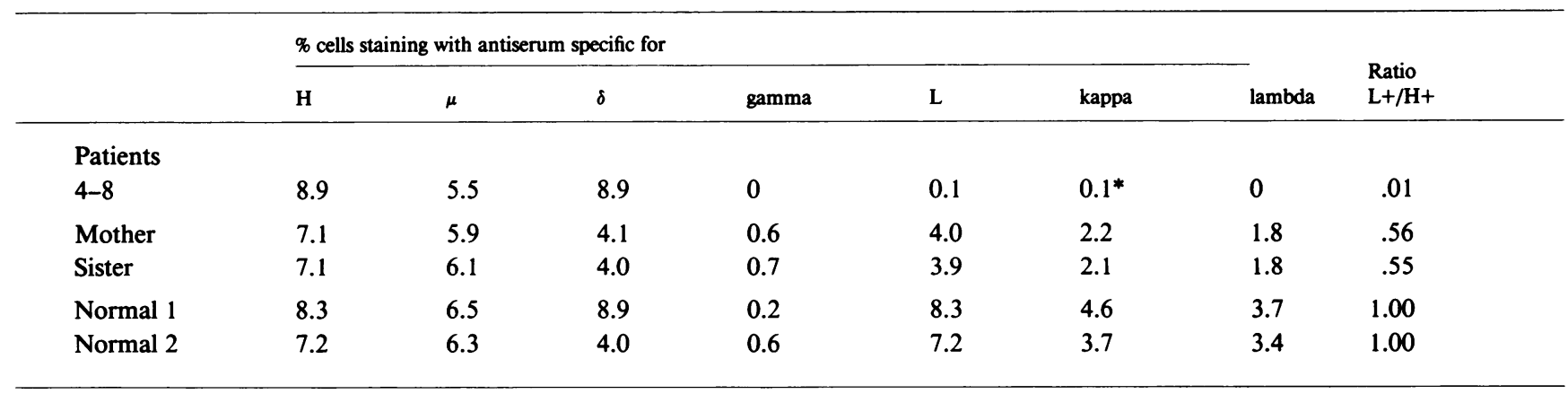

* $0.1 \%$ represents $7 \mathrm{~L}$ chain fluorescent cells (TRITC) out of $500 \mathrm{H}$ chain fluorescent cells (FITC). Peripheral blood cells were also examined with monoclonal antibodies to human kappa and lambda L chains, yielding $6 \mathrm{~L}$ chain fluorescent cells out of $500 \mathrm{H}$ chain fluorescent cells. $500 \mathrm{H}$ chain fluorescent cells were enumerated for each sample. For $\mathrm{L}$ chain enumeration, $\mathrm{H}$ chains were stained with FITC conjugated antisera and L chains were counterstained red with either TRITC or Texas Red conjugated antisera. The numbers shown are for live cells examined for surface Ig expression. Practically identical numbers were found for cytoplasmic fluorescence on fixed cells. 


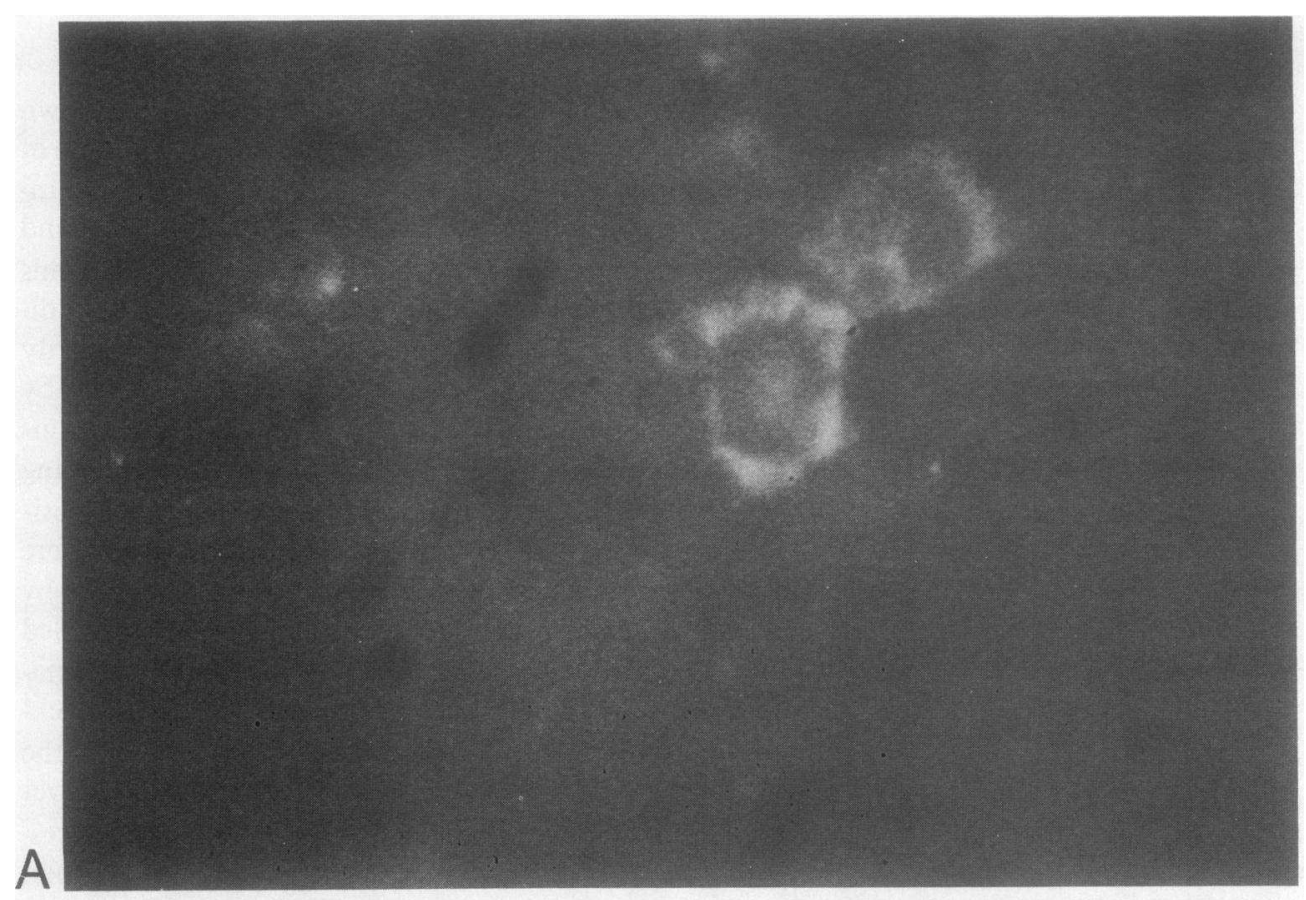

B

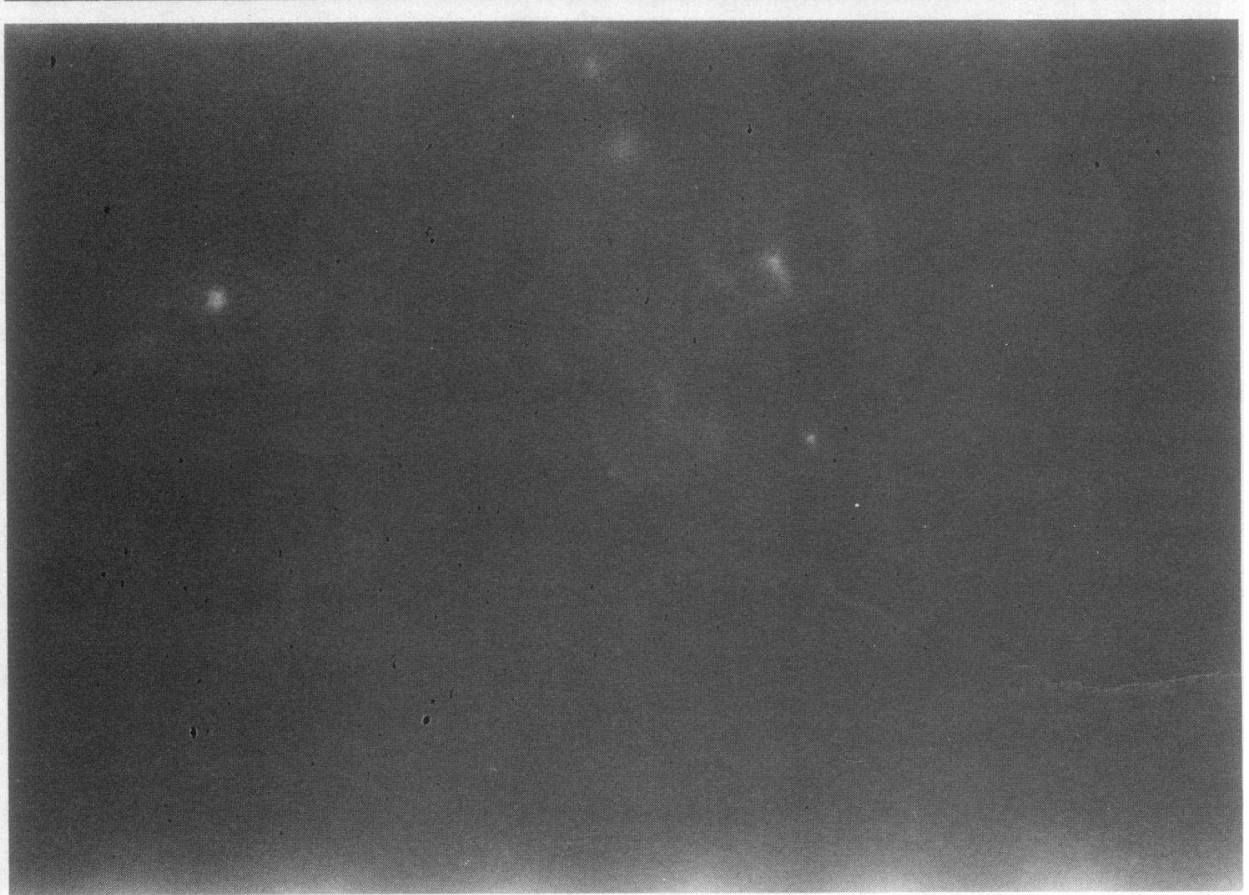

Figure 1. Limited expression of L chain by $B$ cell lines from the XLA patient and his mother. Cells from LAZ 166 (XLA) frozen at the time of isolation were fixed and stained with antiserum to $(a) \mu$ and $\delta$ chains (FITC), and (b) kappa and lambda $L$ chains (Texas Red stain through secondary sheep anti-mouse Ig. For comparison, cells from SMI 4 (normal) were stained with the same antisera: (c) anti $\mu$ and $\delta$, (d) anti kappa and lambda. To test for dimorphic expression of L chain, cells from the LAZ 185 cell line derived from the patient's mother (frozen at the time of establishment) were also examined for $L$ chain expression. Cells stained with antiserum to $(e) \mu, \delta$, and $\gamma \mathrm{H}$ chains and $(f)$ kappa and lambda $\mathrm{L}$ chains. Two cells which fluoresce with anti-H but not anti- $\mathrm{L}$ are marked with white arrows. continuous culture. To determine whether the increasing expression of L chain by LAZ 166 was due to differentiation, we examined cultures of four clones that had been frozen at the time of isolation, and samples that had been in culture for 2-12 mo. Cultures of clones that had been frozen at the time of isolation expressed no L chain (Table III). After 2 mo of continuous culture, clones $\mathrm{C} 7$ and $\mathrm{C} 10$ had 3 and 5\% L chainbearing cells (percentages of $\mathrm{H}$ chain-bearing cells). Cultures of $\mathrm{C} 5$ and $\mathrm{C} 6$ that had been frozen after 6 mo of continuous culture had 42 and $35 \%$ L chain fluorescent cells (representing 5 and $11 \%$ of all cells). After 12 mo in culture, $85 \%$ of $\mathrm{H}$ chain bearing cells from C6 expressed L chain ( $24 \%$ of all cells). The numbers of cells expressing $\mathrm{H}$ chain by $\mathrm{C} 5$ declined to $4 \%$ by 12 mo of culture. These findings suggest that $\mathrm{L}$ chain expres- sion represents delayed differentiation in individual cells rather than overgrowth by rare $\mathrm{L}$ chain-bearing cells.

We examined whether $L$ chain expression by these clones resulted from delayed rearrangement of $\mathrm{L}$ chain genes. Genomic DNA from two clones that were expressing little $\mathrm{L}$ chain (clones $\mathrm{C} 7$ and $\mathrm{C10}$, at 2 mo of continuous culture) were compared with genomic DNA from a clone (C6) and an uncloned culture that had $>30 \%$ cells expressing $\mathrm{L}$ chain $(>80 \%$ of $\mathrm{H}$ chain + cells). Southern blot analysis of Bam $\mathrm{H} 1$ digested DNA probed with the $2.5 \mathrm{~kb}$ genomic kappa chain probe revealed that one of the two alleles was in embryonic configuration and the other allele was rearranged, regardless of whether the cells were producing L chain (Fig. 2). Curiously, the rearranged kappa gene restriction fragment was the same in all 

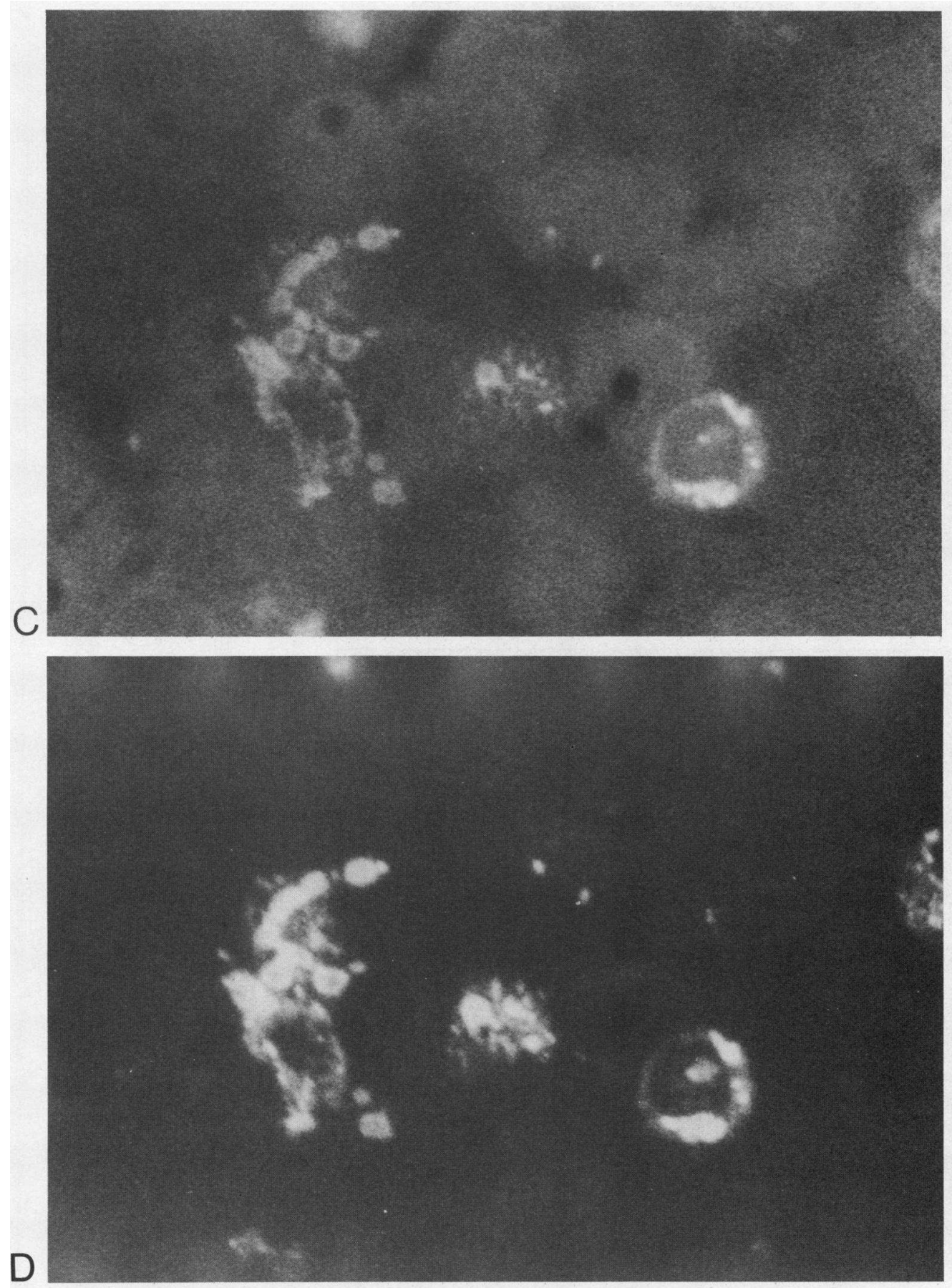

Figure 1 (Continued)

four genomic DNAs. This likely indicates that the same rearrangement was present in all three clones, and in all of the cells of the uncloned culture. Diversity in the genomic DNA of one clone was noted, with the appearance of a second restriction fragment. We were unable to determine whether this additional band resulted from continuing $L$ chain gene rearrangement in culture, after isolation of this clone. The size of this restriction fragment is less than the distance separating Jkappa from Ckappa, suggesting that it results from an abortive rearrangement that deletes Jkappa.

In short summary, this boy's B lymphocytes have an unusual phenotype, composed of limitation to $\delta$ and $\mu$ isotypes, these $\mathrm{H}$ chains are truncated forms translated from $\mathrm{D}-\mathrm{J}_{\mathrm{H}}-\mathrm{C}(\mu \delta)$ intermediate gene rearrangement, and delayed expression of $\mathrm{L}$ chain exclusively of the kappa isotype. Since $\mathrm{D}_{\mu}$ proteins are likely poor inducers of $\mathrm{L}$ chain rearrangement, delayed expression of $\mathrm{L}$ chains in these cells might result from delayed rearrangement of $L$ chain genes. However, we find that in early clones with limited expression of $\mathrm{L}$ chains, one kappa chain gene is rearranged, and that further rearrangement is not necessary for $\mathrm{L}$ chain expression.

Lyonization of $B$ cells in XLA carriers. Based upon the unusual phenotype of this boy's $B$ cells, we examined peripheral lymphocytes and B cell lines of his mother and sister for, first, phenotypic dimorphism and, second, for a clonal basis for the phenotypic dimorphism. 

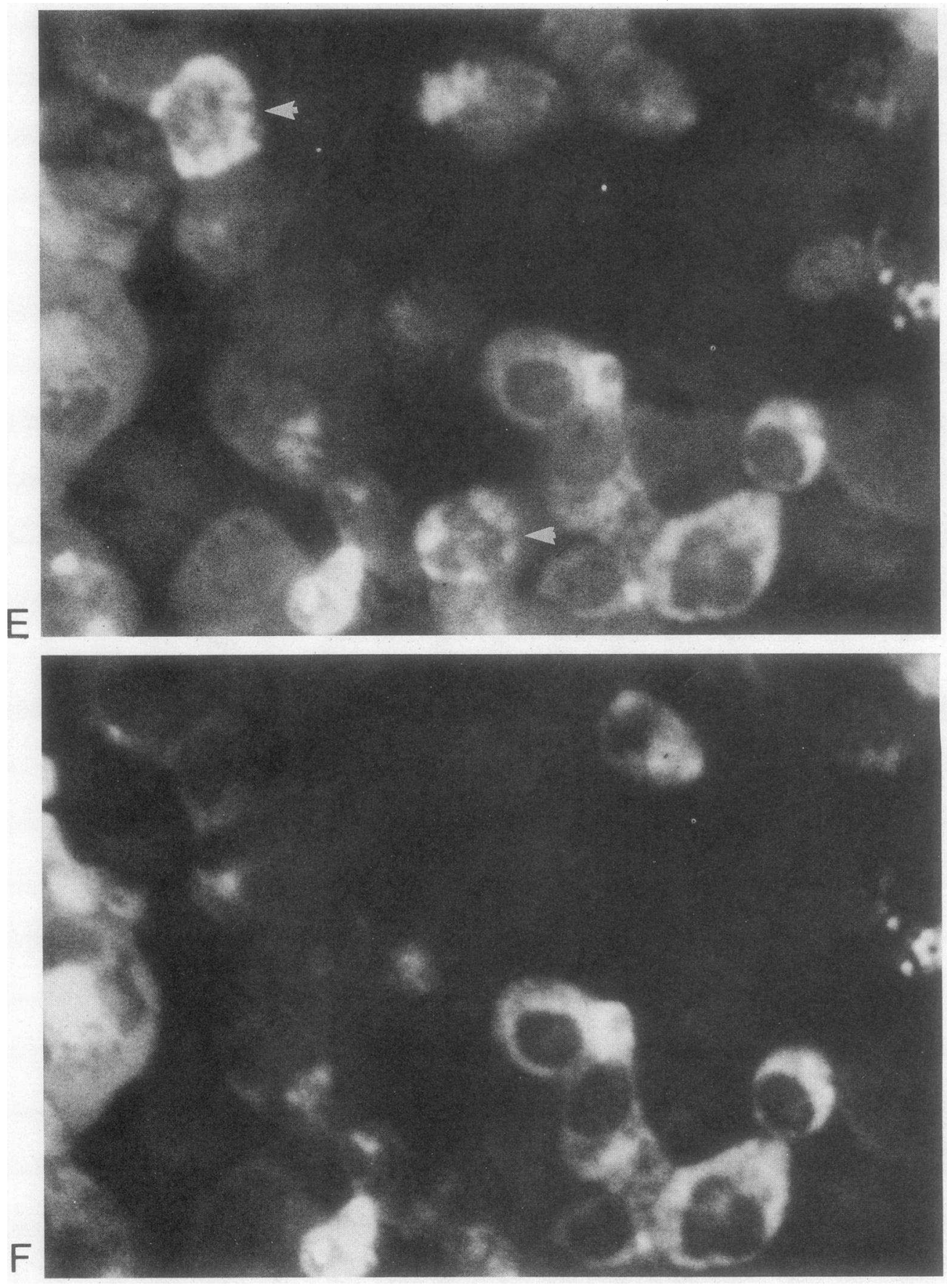

Figure 1 (Continued)

We examined peripheral blood lymphocytes of the patient's mother for the XLA phenotype of expression of $\mathrm{Ig} \mathbf{H}$ chain without associated $\mathrm{L}$ chain. By immune fluorescence, $7.1 \%$ of peripheral blood B lymphocytes expressed $\mathrm{Ig} \mathrm{H}$ chain normally distributed among the $\mu, \delta$, and $\gamma \mathrm{H}$ chain isotypes (Table I). Of the $\mathrm{H}$ chain bearing cells, $44 \%$ ( $3.1 \%$ of total) were without associated $\mathrm{L}$ chain. All of the cells that expressed $\gamma \mathrm{H}$ chain also expressed $\mathrm{L}$ chain. The peripheral blood of the patient's sister had 7.1\% B lymphocytes, normally distributed among the $\mu, \delta$, and $\gamma \mathrm{H}$ chain isotypes. $45 \%$ did not have light chain (3.9\% of total) (Table I), indicating that she had a dimorphic population of B lymphocytes. As seen with her mother's cells, all of the $\gamma$-bearing cells expressed $\mathrm{L}$ chain.
Two independently established B cell lines from the peripheral blood of the mother (LAZ 185 and SAM 25) were examined for dimorphic expression of $L$ chains. Early cultures of these cell lines included 51 and $52 \% \mathrm{H}$ chain-bearing cells, but only 34 and $28 \%$ cells with associated L chains (Table II, Fig. 1). As with peripheral blood lymphocytes, all of the $\gamma \mathrm{H}$ chain-bearing cells also expressed $L$ chain. After several months of continuous culture, a subline of LAZ 185 became almost exclusively $\gamma \mathrm{H}$ chain bearing, and almost all of the $\mathrm{H}+$ cells expressed $\mathrm{L}$ chain. Clones isolated from this subline were exclusively of the $\gamma+\mathrm{L}+$ normal phenotype. In contrast, several clones established from early cultures of LAZ 185 were exclusively of the $\delta+$ or $\delta+\mu+$ phenotype, characteristic of the 


\begin{tabular}{|c|c|c|c|c|c|c|c|c|}
\hline & \multicolumn{7}{|c|}{$\%$ cells fluorescent with antiserum to } & \multirow{2}{*}{$\begin{array}{l}\text { Ratio } \\
\mathrm{L}+/ \mathrm{H}+\end{array}$} \\
\hline & $\mathrm{H}$ & $\mu$ & $\delta$ & gamma & $\mathrm{L}$ & kappa & lambda & \\
\hline \multicolumn{9}{|l|}{ X-LA } \\
\hline LAZ 166 & 28 & 8 & 28 & 0 & 0 & 0 & 0 & 0 \\
\hline SB 25 & 34 & 5 & 34 & 0 & 4 & 4 & 0 & 0.12 \\
\hline \multicolumn{9}{|l|}{ Carriers } \\
\hline $\begin{array}{l}185 \\
\text { (mother) }\end{array}$ & 52 & 14 & 21 & 25 & 34 & 14 & 20 & 0.65 \\
\hline $\begin{array}{l}\text { SAM } 25 \\
\text { (mother) }\end{array}$ & 51 & 27 & 29 & 23 & 28 & ND & ND & 0.55 \\
\hline $\begin{array}{l}\text { SAM } 5 \\
\text { (sister) }\end{array}$ & 68 & 28 & 31 & 33 & 35 & ND & ND & 0.51 \\
\hline \multicolumn{9}{|l|}{ XLA clones } \\
\hline $166 \mathrm{C} 5$ & 12 & 12 & 12 & 0 & 0 & 0 & 0 & 0 \\
\hline $166 \mathrm{C} 6$ & 28 & 0 & 28 & 0 & 0 & 0 & 0 & 0 \\
\hline $166 \mathrm{C7}$ & 33 & 33 & 33 & 0 & 0 & 0 & 0 & 0 \\
\hline $166 \mathrm{C} 10$ & 35 & 0 & 35 & 0 & 0 & 0 & 0 & 0 \\
\hline \multicolumn{9}{|l|}{ Carrier clones } \\
\hline 185 gamma & 33 & 0 & 0 & 33 & 32 & 0 & 32 & 0.98 \\
\hline $185 \mathrm{~S} 1 \mathrm{~A}$ & 35 & 0 & 35 & 0 & 0 & 0 & 0 & 0 \\
\hline 185S1D & 44 & 7 & 44 & 0 & 1.3 & 1.3 & 0 & 0.03 \\
\hline \multicolumn{9}{|l|}{ Normal } \\
\hline SMI 4 & 12 & 12 & 2 & 0 & 13 & 0 & 13 & 1.00 \\
\hline 007 C4.4 & 40 & 0 & 0 & 40 & 41 & 41 & 0 & 1.00 \\
\hline
\end{tabular}

Fluorescence was determined on cell lines and clones either at the time of establishment or at a later time on a sample of cells frozen at the time of establishment (for clones, samples taken at the time of isolation were used). Cells were placed on cytocentrifuge slides, fixed, and stained with contrasting fluorochromes to determine percentages. For $\mathrm{L}$ chain enumeration, the cells were stained with antiserum to $\mathrm{H}$ chain $(\mu, \delta$, and $\gamma$ ), and counterstained with antiserum to kappa or lambda isotypes (antisera), or to both kappa and lambda isotypes (monoclonal antibodies). $500 \mathrm{H}$ chain bearing cells were examined for each sample. ND, kappa/lambda percentages were not determined for SAM 25 and SAM 5.

Table III. L Chain Expression in Culture

\begin{tabular}{lrrrr}
\hline & \multicolumn{5}{c}{ \% L chain expressing cells after culture for: } \\
\cline { 2 - 5 } & 0 mo & 2 mo & 6 mo & 12 mo \\
\hline LAZ 166 & 0 & 2 & 48 & 82 \\
166 C5 & 0 & NT & 42 & $\mathrm{NT}^{\ddagger}$ \\
166 C6 & 0 & NT & 38 & 85 \\
166 C7 & 0 & 3 & NT & NT \\
166 C10 & 0 & 5 & $12^{*}$ & NT \\
185 S1A & 0 & NT & $13^{*}$ & 72 \\
185 S1D & 1 & NT & 24 & NT \\
007 C4.4 & 100 & 100 & 100 & 100 \\
\end{tabular}

Figures are percentage of $H$ chain bearing cells that express $L$ chains. $\mathrm{H}$ chain bearing cells were identified by fluorescence with FITC conjugated antisera to $\delta, \mu$, and gamma $H$ chains, and $L$ chain bearing cells identified by counterstaining with Texas Red conjugated antisera to kappa and lambda $\mathrm{L}$ chains. $500 \mathrm{H}$ chain bearing cells were examined for each sample.

* This percentage was determined after 4 mo of continuous culture.

¥ Percentage of cells producing $\mathrm{H}$ chain declined with continued culture from an initial 12 to $4 \%$ by $12 \mathrm{mo}$.

NT, not tested. patient's B cell phenotype. Early cultures of these clones did not express L chain. As was found with the patient's B cell lines, several months in continuous culture resulted in gradual expression of $\mathrm{L}$ chain, exclusively of the kappa isotype (Table III).

Early cultures of a B cell line established from peripheral blood of the sister (SAM 5) contained $68 \%$ cells bearing $\delta, \mu$, or $\gamma \mathrm{H}$ chain, but only $35 \%$ cells bearing $\mathrm{L}$ chain (Table II), further indicating that she is a carrier of XLA. All of the $\gamma \mathrm{H}$ chain-bearing cells expressed $L$ chain.

We determined the sizes of the Ig proteins produced by B cell lines and clones from the mother and sister. In SDS-acrylamide gels, three Ig $\mathrm{H}$ chain bands were precipitated by Staph A from ${ }^{35} \mathrm{~S}$-labeled cultures and culture supernatants from both the mother's and the sister's B cell lines (Fig. 3). Based upon molecular weights, we identified these bands as normal $\mu$ chain, truncated XLA $\mu$ chain and comigrating normal $\gamma$ chain, and truncated XLA $\delta$ chain. Immune precipitation with second antibody instead of Staph A confirmed the assignments of these three bands. Precipitation with antiserum to $\mu$ heavy chain resulted in two bands, a normal sized $\mu$ chain band and a truncated $\mu$ chain band. Precipitation with antiserum to $\gamma$ chain resulted in a single band that comigrated with the truncated $\mu$ chain. Precipitation with antiserum to $\delta$ chain yielded the single truncated $\delta$ chain band. Since we used cells that had 


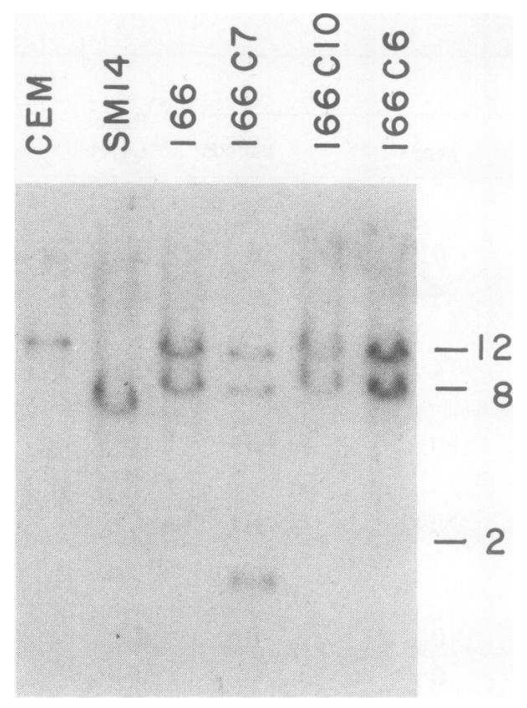

Figure 2. Southern blot of genomic DNA digested with Bam HI and probed for kappa L chains (Ckappa). To determine whether delayed kappa gene rearrangement caused limited expression of $L$ chain by XLA B cells, kappa chain genes were probed from a cell line and a clone which had more than $80 \%$ of $\mathrm{H}+$ cells expressing $\mathrm{L}$ chain (LAZ 166 and clone C6) in comparison to two clones which had essentially no $\mathrm{L}$ chain expressing cells (clones $\mathrm{C} 7$ and $\mathrm{C10}$ ). Genomic DNA from the normal B cell line SMI4 was examined for rearranged genes, and from the $\mathrm{T}$ cell line CEM for embryonic kappa genes.

been in culture for at least $6 \mathrm{mo}$, Ig L chains were present as well. They migrated with normal $\mathrm{L}$ chains at $23,000 \mathrm{D}$.

We examined the $\mu$ and $\delta \mathrm{H}$ chains of B cell clones that had shown delayed expression of $L$ chains as a test of the clonal expression of the XLA phenotype. Clones S1A and S1D from the LAZ 185 cell lines bore the XLA phenotype of delayed

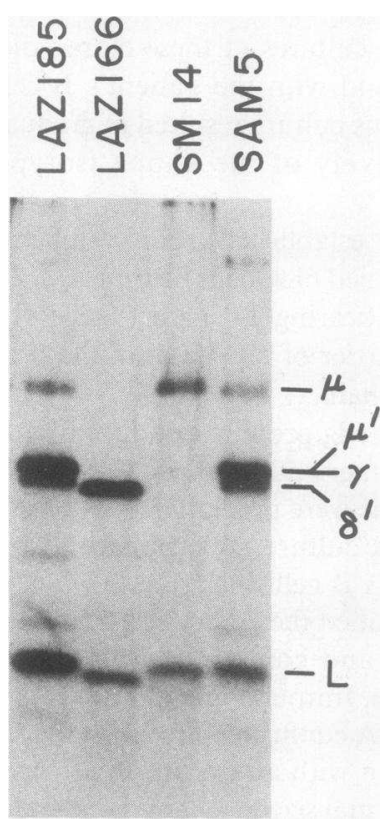

Figure 3. SDS acrylamide gel of immunologically precipitated $\mathrm{Ig}$ proteins. To test for phenotypic heterogeneity Ig proteins produced by B cell lines from the patient's mother and sister, cell lines supernatants (secreted proteins) labelled with [35S]methionine were precipitated with antiserum to $H$ chain $(\mu, \delta$, and gamma specificities) and Staph A, and electrophoresed in a $12.5 \%$ acrylamide slab gel. LAZ 185 was derived from the patient's mother, LAZ 166 was derived from the patient, SAM 5 was established from the patient's sister, and SMI4 is a normal B cell line which produces $\mu$ chain. All of the cell lines had been in culture for several months (LAZ 166 for $1 \mathrm{yr}$ ) at the time of this experiment, making $L$ chain expression by the XLA phenotypic cells likely. Since Staph A alone precipitated all of the Igs shown, the three $H$ chain bands from LAZ 185 and Sam 5 were identified as $\mu, \mu^{\prime}$, gamma, and $\delta^{\prime}$ by indirect precipitation with goat antiserum to rabbit IgG substituted for Staph A. Identical bands were identified in cell lysates from these cultures.

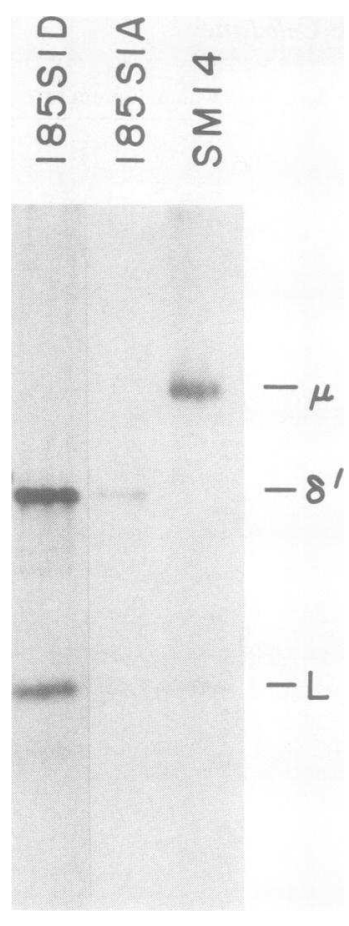

Figure 4. Identification of truncated $\delta$ chains from B cell line clones from the patient's mother. Clones SID and $\mathrm{S} 1 \mathrm{~A}$ isolated from the LAZ 185 cell line were found to express predominantly $\delta \mathrm{H}$ chain with limited expression of $\mathrm{L}$ chain. After 6 mo in culture, the cells were found to express kappa L chain (Table III). Ig proteins from these cultures were examined by SDS acrylamide gel electrophoresis as described in Fig. 3. $\delta^{\prime}$ (truncated) and $\mathrm{L}$ chain were the only Ig proteins identified, in comparison to the fulllength $\mu$ chain from the SMI4 normal $\mathrm{B}$ cell line.

expression of $\mathrm{L}$ chain, exclusively of the kappa isotype, and limitation of $\mathrm{H}$ chain to predominantly the $\delta$ isotype with some $\mu$ chain. Immunoglobulin proteins from cultures of these clones that had been in culture for more than $1 \mathrm{yr}$ were examined by SDS-acrylamide gel electrophoresis of immunoprecipitated proteins (Fig. 4). Both clones produced truncated $\delta \mathrm{H}$ chains that comigrated with the truncated $\delta$ chain of LAZ 166 clone $\mathrm{C} 6$. For comparison, we examined the immunoglobulin proteins of clone $\mathrm{Cl}$ isolated from the $185 \mathrm{gamma}+$ subline of LAZ 185. This subline, as well as the clone, expressed $\mathrm{L}$ chain from the time of isolation. A full length gamma chain was identified (data not shown).

\section{Discussion}

We have demonstrated the delayed expression of $L$ chain, exclusively of the kappa isotype, by the B lymphocytes and B cell lines derived from a boy with the minor form of XLA. The delayed expression of $\mathrm{L}$ chain is clonal; suggesting that it results from differentiation rather than selective overgrowth by rare $\mathrm{L}$ chain producing cells. Further, the eventual expression of $L$ chain does not result from delayed rearrangement of kappa $L$ chain variable region genes. This delayed expression of $L$ chain, associated with production of truncated $\mathrm{H}$ chains only of the $\delta$ and $\mu$ isotypes, resulting from incomplete variable region gene rearrangement (Schwaber, J., and R. Chen, submitted for publication), provides an unusual phenotype of XLA B cells from this patient. Based upon this unusual phenotype, we have tested for and found cellular evidence for Lyonization (13) in the peripheral blood B lymphocytes of his mother and identified his sister as a carrier of XLA. This demonstration rests upon the prediction that her peripheral blood B lymphocytes should be a clonal mixture of cells with normal phenotype (normal $\mathrm{X}$ chromosome active), and of cells with the XLA B cell phenotype of her son (XLA X chromosome 
active). Both peripheral blood B lymphocytes and B cell lines from the patient's mother showed dimorphism, approximately half of the cells of normal phenotype, the other half with the phenotype of her XLA son's cells. B cell line clones with delayed expression of $\mathrm{L}$ chain, were limited to $\delta$ and $\mu \mathrm{H}$ chain isotypes, and two clones examined produced truncated $\delta$ chain. We tested for and found dimorphism in the patient's sister, indicating that she is likely a carrier of the $\mathrm{X}$ chromosome with the locus for XLA.

The phenotype of this boy's B cells is different from the more common phenotype associated with a failure of $B$ cell development at the stage of pre-B cells $(8,9)$. Whether the two forms of XLA are allelic is not known. We have proposed that the phenotype of this boy's B cells results from a central failure of $V_{H}$ rearrangement with preformed $D-J_{H}$ intermediates (Schwaber, J., and R. Chen, submitted for publication). The size and sequence of his $\mathrm{H}$ chains is different from the $\mu$ chains of pre-B cells from the major form of XLA (12). Yet, individuals with this minor XLA phenotype have been described in the same family as individuals with the major XLA phenotype (2).

There is delayed expression of $\mathrm{L}$ chain in the $\mathrm{B}$ cells from this boy. There are rare $L$ chain expressing cells in vivo, and recently established B cell lines have similarly limited $L$ chain expression. With continuing time in culture, B cells express $\mathrm{L}$ chains exclusively of the kappa isotype. Expression of L chains in vitro does not directly result from kappa gene rearrangement. We cannot exclude the possibility that peripheral blood $B$ cells have not undergone $L$ chain gene rearrangement. However, we found one kappa gene rearranged in cell clones regardless of whether they produced $\mathrm{L}$ chain. $\mathrm{L}$ chain expression by the B cells is associated with increased production of $\mathrm{H}$ chain. Alt and co-workers $(28,29)$ have proposed that the sequence of Ig gene rearrangement is regulated by the protein products of the previous step in rearrangement. L chain gene rearrangement in these cells may occur independent of the usual induction processes, and increased $\mathrm{D} \mu$ production may be necessary for induction of expression.

Based upon the phenotype of this patient's XLA B cells, we have tested for and found evidence for Lyonization of the $B$ cells of his mother and sister. Lyon's hypothesis (13) predicts that in a female XLA heterozygote, $50 \%$ of the clonal precursors of B lymphocytes should be of each phenotype. With only a few exceptions, enzymes encoded on mammalian $\mathrm{X}$ chromosomes follow this prediction (30-32). Failure of differentiated cells to follow this prediction has been observed in Wiskott-Aldrich syndrome $(33,34)$ and Lesch-Nyhan syndrome $(35,36)$, and is thought to result from selective growth disadvantage of cells expressing the affected $X$ chromosome. In the major form of XLA, recent evidence has shown that there is a failure of cells in which the affected $\mathrm{X}$ chromosome is active to elaborate $B$ cells $(14,15)$. This is consistent with the failure to differentiate beyond pre-B cells in those patients $(8,9)$. In this XLA patient, however, immature $B$ cells are present in peripheral circulation in normal numbers $(6,7)$. The presence of XLA phenotypic B cells in peripheral blood of his mother is consistent with the behavior of her son's B cells.

This patient's family has been found to be homozygous for all $\mathrm{X}$ chromosome linked markers tested, including $\mathrm{Xg}$, G6PD, HPRT, and the two restriction fragment polymorphisms used to assign linkage of the major form of XLA to Xq2 (12). We have not tested for heterozygosity of the HPRT and PGK genes based upon methylation pattern (15). We would suggest that the clonal dimorphism found in the patient's mother likely results from Lyonization. The patient's B cells are frozen at the stage of D-J-C $(\delta \mu) \mathrm{H}$ chains, with delayed expression of only kappa $\mathrm{L}$ chain. In contrast, Abelson virus transformed pre-B cells producing D-J-C $\mu$ H chain spontaneously differentiate in culture to production of $\mathrm{V}-\mathrm{D}-\mathrm{J}-\mathrm{C} \mu$, that is, mature $\mu \mathrm{H}$ chain, associated with $\mathrm{L}$ chain (37). Similar to the patient's cells, we have been unable to find evidence for differentiation of the XLA phenotypic B cells from the patient's mother. We suggest that the presence of $B$ cells with this phenotype in the carriers of this form of the disease results from the genetic failure of variable region gene rearrangement intrinsic to the patient's B cells.

The cellular evidence for Lyonization in carriers of this form of XLA suggests that the disease is intrinsic to the $B$ lymphocytes. A growth disadvantage of XLA B lymphocytes, due either to failure of the cells to diversify or from absence of antigen directed amplification, could have resulted in reduced numbers of XLA phenotypic B cells. We have not found a significant growth disadvantage of the XLA B cells in peripheral blood of the XLA carriers. This observation is in accord with recent findings that the pool of peripheral blood lymphocytes has a very short half-life (38). Because of the absence of complete antigen receptors, it further suggests that the shortlived B lymphocytes do not result from antigen driven amplification. Deviations of the heterogeneity observed in peripheral blood from a near 50\% normal and XLA phenotype would be expected in populations of cells that had responded to antigenic stimulation, such as spleen and lymph node (39).

The population of peripheral blood B lymphocytes and B cell lines from the XLA patient's mother and sister results from mixture of clonally derived cells at several stages of $B$ lymphocyte differentiation, some of normal, some of XLA phenotype. All of the IgG bearing B cells are of normal phenotype, including expression of $\mathrm{L}$ chains of either kappa or lambda isotype. $\delta$ and $\mu$-bearing cells in mother and sister are heterogeneous, including XLA phenotype cells without $\mathrm{L}$ chains, which contribute truncated $\mu$ and $\delta$ chains, and normal phenotype cells with $\mathrm{L}$ chains contributing full-sized $\mu$ chains. Since we have never observed $\delta$ chain production by internal labeling of normal B cell lines, it is not surprising that comparable quantities of normal sized $\delta$ heavy chain are not detected.

A selective advantage for growth of cells with normal phenotype was observed in mass culture of B cell lines from the XLA carriers. Under cloning conditions, cells with the XLA phenotype were apparently overrepresented, both in the two clones described and in 10 additional clones examined only by immune fluorescence. The cells with normal phenotype were able to grow under cloning conditions, as indicated by our isolation of normal clones from the subline in which normal phenotype cells had replaced XLA phenotype cells. The basis for these differential growths is not known.

Demonstration of Lyonization in the B lymphocytes of the mother and half-sister of a patient with X-linked agammaglobulinemia implies that this disease results from a defective $\mathrm{X}$ chromosome locus whose effects are intrinsic to the B lymphocytes, rather than from a failure of an extrinsic factor (2). There is a failure of $B$ cell development in XLA, which is associated in this form of XLA with incomplete $\mathrm{H}$ chain gene V-D-J rearrangement. This failure of gene rearrangement may be the primary defect in this disease, or may be secondary to a 
failure of B lymphocyte receptors to properly signal for the next step in Ig $\mathrm{H}$ chain gene rearrangement.

\section{Acknowledgments}

The continued support and interest of Fred Rosen is gratefully acknowledged, as well as the technical assistance of Barbara Malone.

Supported by grants from the U. S. Public Health Service (AI-21165, 21163, and RR-02172), and a grant from the March of Dimes-Birth Defects Foundation. Dr. Schwaber is an Established Investigator of the American Heart Association.

\section{References}

1. Bruton, O., 1953. Agammaglobulinemia (congenital absence of gamma globulin). Report of a case, Medical Annals of the District of Columbia. 22:648-652.

2. Rosen, F., M. Cooper, and R. Wedgwood. 1984. The primary immunodeficiencies. N. Engl. J. Med. 311:235-242.

3. Gitlin, D., W. Hitzig, and C. Janeway. 1956. Multiple serum protein deficiencies in congenital and acquired agammaglobulinemia. J. Clin. Invest. 35:1199-1204.

4. Rosen, F., R. Wedgwood, F. Auiti, M. Cooper, R. Good, L. Hanson, W. Hitzig, S. Matsumoto, M. Seligmann, J. Soothill, and T. Waldmann. 1983. Primary immunodeficiency diseases, report of a WHO Expert Committee. Clin. Immunol. Immunopath. 28:450-475.

5. Siegal, F., B. Pernis, and H. Kunkel. 1971. Lymphocytes in human immunodeficiency states: a study of membrane associated immunoglobulins. Eur. J. Immunol. 1:482-486.

6. Geha, R., F. Rosen, and E. Merler. 1973. Identification and characterization of subpopulations of lymphocytes in human peripheral blood after fractionation on discontinuous gradients of albumin. $J$. Clin. Invest. 52:1726-1737.

7. Schwaber, J., H. Lazarus, and F. Rosen. 1978. Restricted classes of immunoglobulin produced by a lymphoid cell line from a patient with agammaglobulinemia. Proc. Natl. Acad. Sci. USA. 75:2421-2423.

8. Pearl, E., L. Vogler, A. Okos, W. Crist, A. Lawton, and M. Cooper. 1978. B lymphocyte precursors in human bone marrow. $J$. Immunol. 120:1169-1175.

9. Schwaber, J., H. Molgaard, S. Orkin, H. Gould, and F. Rosen. 1983. Early pre-B cells from normal and X-linked agammaglobulinemia produce $\mathrm{Cmu}$ without associated variable region. Nature (Lond.). 302:355-358.

10. Sanger, R., and R. Race. 1963. Xg blood groups and familial hypogammaglobulinemia. Lancet. i:859-862.

11. Rosen, F., G. Hutchison, and F. Allen. 1965. Xg blood groups and congenital hypogammaglobulinemia. Vox Sang. 10:729-735.

12. Kwan, S. P., L. Kunkel, G. Bruns, R. Wedgwood, S. Latt, and F. Rosen. 1986. Mapping of the X-linked agammaglobulinemia locus by use of restriction fragment length polymorphism. J. Clin. Invest. 77:649-652.

13. Lyon, M. F. 1961. Gene action in the X-chromosome of the mouse (mus musculus L.). Nature (Lond.). 190:370-372.

14. Conley, M., P. Brown, A. Pickard, R. Buckley, D. Miller, W. Raskind, J. Singer, and P. Fialkow. 1986. Expression of the gene defect in X-linked agammaglobulinemia. N. Engl. J. Med. 315:564-567.

15. Fearon, E., J. Winkelstein, C. Civin, D. Pardoll, and B. Vogelstein. 1987. Carrier detection in X-linked agammaglobulinemia by analysis of X-chromosome inactivation. N. Engl. J. Med. 316:427431.

16. Schwaber, J., and F. Rosen. 1979. Induction of synthesis and secretion of human immunoglobulin in a somatic cell hybrid between mouse myeloma and lymphocytes from patients with agammaglobulinemia. J. Exp. Med. 148:974-986.

17. Schwaber, J., and F. Rosen. 1982. Isotypes of surface immuno- globulin on B lymphocytes from patients with immune deficiency. $J$. Clin. Immunol. 2:30-33.

18. Boyum, A. 1976. Isolation of lymphocytes, granulocytes, and macrophages. Scand. J. Immunol. 5(Suppl. 5):9-45.

19. Schwaber, J., H. Lazarus, and F. Rosen. 1978. Bone marrowderived lymphoid cell lines from patients with agammaglobulinemia. J. Clin. Invest. 62:302-313.

20. Hoch, S., P. Schur, and J. Schwaber. 1982. Improved method for cloning human B cell lines. Cell. Immunol. 72:219-230.

21. Hart, D. 1975. Studies on Nonidet P 40 lysis of murine lymphoid cells. J. Immunol. 115:871-875.

22. Horwitz, M., and M. Scharff. 1969. In Fundamental Techniques of Virology. K. Habel and N. Salzman, editors. Academic Press, New York. 297-315.

23. Dreyfuss, G., S. Adam, and Y. Choi. 1984. Physical changes in cytoplasmic messenger ribonucleoproteins in cells treated with inhibitors of mRNA transcription. Mol. Cell. Biol. 4:415-422.

24. Maniatis, T., E. Fritsch, and J. Sambrook. 1982. Molecular Cloning, Cold Spring Harbor Laboratory, New York.

25. Southern, E. 1979. Gel electrophoresis of restriction fragments. Methods Enzymol. 68:152-176.

26. Hieter, P., E. Max, J. Seidman, J. Maizel, and P. Leder. 1980. Cloned human and mouse kappa immunoglobulin constant and $\mathrm{J}$ region genes conserve homology in functional segments. Cell. 22:197207.

27. Feinberg, A., and B. Vogelstein. 1983. A technique for radiolabeling DNA restriction fragments to high specific activity. Anal. Biochem. 132:6-13.

28. Reth, M., and F. Alt. 1984. Novel immunoglobulin heavy chains are produced from $\mathrm{DJ}_{\mathrm{H}}$ gene segment rearrangements in lymphoid cells. Nature (Lond.). 312:418-423.

29. Blackwell, T., M. Moore, G. Yanccopoulos, H. Suh, S. Lutzker, E. Selsing, and F. Alt. 1986. Recombination between immunoglobulin variable region segments is enhanced by transcription. Nature (Lond.). 324:585-588.

30. Keitges, E., M. Rivest, M. Siniscalco, and S. Gartler. 1985. X linkage of steroid sulphatase in the mouse is evidence for a functional Y linked allele. Nature (Lond.). 315:226-227.

31. Ducos, J., Y. Marty, R. Sanger, and R. Race. 1971. Xg and chromosome inactivation. Lancet. ii:19-20.

32. Goodfellow, P., G. Banting, D. Sheer, H. Ropers, A. Caine, M. Ferguson-Smith, S. Povey, and R. Voss. 1983. Genetic evidence that a $\mathrm{Y}$ linked gene in man is homologous to a gene on the $\mathrm{X}$ chromosome. Nature (Lond.). 302:346-349.

33. Gealy, W., J. Dwyer, and J. Harley. 1980. Allelic exclusion of glucose 6 phosphate dehydrogenase in platelets and T lymphocytes from a Wiskott-Aldrich syndrome carrier. Lancet. 1:63-65.

34. Prchal, J., A. Carroll, and J. Prchal. 1980. Wiskott-Aldrich syndrome: cellular impairments and their implication for carrier detection. Blood. 56:1048-1054.

35. Salzman, J., R. DeMars, and P. Benke. 1968. Single allele expression at an X-linked hyperuricemia locus in heterozygous human cells. Proc. Nat. Acad. Sci. USA. 60:545-549.

36. McDonald, J., and W. Kelley. 1972. Lesch-Nyhan syndrome: absence of the mutant enzyme in erythrocytes of a heterozygote for both normal and mutant hypoxanthine-guanine phosphoribosyl transferase. Biochem. Genet. 6:21-26.

37. Reth, M., P. Ammirati, S. Jackson, and F. Alt. 1985. Regulated progression of a cultured pre-B cell line to the B cell stage. Nature (Lond.). 317:353-355.

38. Freitas, A., B. Rocha, and A. Coutinho. 1986. Life span of B lymphocytes: the experimental basis for conflicting results. J. Immunol. 136:470-476.

39. Douglas, S. 1976. In Basic \& Clinical Immunology. H. Fudenberg, D. Stites, J. Caldwell, and J. Wells, editors. Lange Medical Publications, Los Altos, CA. 70-87. 